\title{
STUDY ON SEROPREVALENCE OF MUMPS - SPECIFIC IGG ANTIBODIES IN A HEALTHY POPULATION
}

\author{
Karcheva M.*, M. Atanasova, I. Makaveev*, M. Daskalova* \\ * Department of Epidemiology, Parasitology and Tropical Medicine, \\ Department of Anatomy, Histology, Cystology and Biology, \\ Medical University - Pleven, Bulgaria
}

\section{SUMMARY}

Mumps is a vaccine preventable viral infection. Its typical clinical manifestations are characterized by pain and swelling of the salivary glands, fever, and fatigue. Often other organs are affected - testes in males after puberty (orchitis), ovaries in women (ooforitis), pancreas (pancreatitis), central nervous system (meningities). The use of specific immune prophylaxis led to a significant success in the fight against mumps, but there are still unresolved issues related to the immunological and epidemiological effectiveness of the vaccines. The disease continues to interest researchers today. The main issues being tackled are related to the conduct of virological, clinical and seroepidemiological studies in different countries. Objectives of the study is to determine the frequency distribution of mumps-specific $\operatorname{IgG}$ antibodies in healthy populations in the region of Pleven, Bulgaria. Methods: a cross-sectional sero - epidemiological representative population - based survey in the area was made. Enzyme immunoassay method was used for an indirect proof of mumps - specific IgG serum antibodies. 410 people were examined at an average age of 25 (1 to 84). Of these, 250 (61\%) were women and 160 (39 $\%)$ - men. Results: Of all test results, the negative were 72 (19\%), the borderline were $12(3 \%)$, the positive were 182 (44\%), and highly positive were 144 (35\%). The vaccination status showed that $242(69 \%)$ of all surveyed were immunized with a vaccine against mumps. According to the immunization schedule in Bulgaria, 132 (33\%) people were immunized with monovaccine during the years - 1 intake, 80 $(20 \%)$ with trivaccine - 1 intake, and 64 (16\%) - 2 doses. Conclusion: We believe that despite the specific immunprophylaxis carried out against mumps decades on end, the necessary level of protection leading to its elimination has not yet been reached.

Key words: mumps, seroprevalens, immunprophylaxis

\section{INTRODUCTION:}

Mumps infection is widespread worldwide. In recent years, outbreaks have occurred in countries with mandatory immunization - UK, Ireland, Austria, Spain, USA, Canada and others $[1,2,3,8,9,12,13]$. The spread of mumps in Bulgaria is not significantly different from the situation in the other European countries having introduced two dosage immunization regimens, namely registration of outbreaks involving adolescents and young adults $[1,4,7,10,11]$.

The growth intensity of an infectious disease epidemic process depends on the level of collective immunity. Collective immunity as an expression of epidemiological population immunity is present when there is natural or artificial immunity of the whole population or at least $80-85 \%$ of it. In these cases, we talk about an immune stratum, i.e. population distribution according to different levels of individual immunity. This immunologic structure of the population shows what percentage of it has immunity, respectively susceptibility to an infection. It is assumed that the more numerous an immune stratum is, the more limited is the infection ability to spread among the public and vice versa [6].

In recent years, outbreaks of mumps in many countries, including ours, show a high percentage of immunized infected persons [5]. This requires making sero epidemiological studies [9].

\section{AIMS:}

To determine the frequency distribution of specific IgG antiparotid antibodies among healthy population in Pleven, Bulgaria.

\section{MATERIALAND METHODS:}

A cross - sectional, sero - epidemiological representative population study in Pleven was made. Participation in the survey was voluntary with guaranteed confidentiality. A questionnaire was developed by which we gathered information on gender, age and immunization status regarding mumps. The participants had venous blood taken by qualified personnel for serological testing. The obtained sera were stored at $-20^{\circ} \mathrm{C}$ before testing them. Was administered an enzyme immunoassay test as instructed by the producer Orgenium Laboratories (FINLAND). Mumps IgG Antibody EIA75 was used, intended for semi - 
quantitative serum determination of specific IgG mumps antibodies.

The obtained results were interpreted in the context of epidemiological information and the purpose of the study. 410 persons were examined, average age 25 ( 1 to 84 ). Of these, $250(61 \%)$ women and $160(39 \%)$ - men.

\section{RESULTS AND DISCUSSION:}

Of the total number of tested individuals negative results were shown by $72(19 \%), 12(3 \%)$ were borderline,
$182(44 \%)$ were positive and 144 (35\%) - high positive (Table 1).

The distribution of tested persons according to vaccination status is presented in Fig. 1.

As seen from the chart, immunized individuals are $69 \%$ (242) of all surveyed. According to the immunization calendar of the country over the years they have been immunized with vaccines of which 16 percent have been reimmunized.

Table 1. Seroprevalence of mumps specific IgG antibodies in the tested individuals

\begin{tabular}{|c|c|c|c|}
\hline Benchmarks (S/co ratio) & Results & Number (n) / Ratio/ (\%) & Interpretation \\
\hline$<0.8$ & $\mathbf{0 . 1 0 8 - 0 . 7 8 8 ( 0 . 4 4 6 \pm 0 . 2 2 )}$ & $72(19)$ & Negative \\
& $0.824-0.922$ & $12(3)$ & Borderline \\
\hline $0.8-0.99$ & $(0.871 \pm 0.04)$ & & Positive \\
& $1.015-6.190$ & $182(44)$ & \\
\hline $1-4$ & $(2.384 \pm 0.88)$ & & High positive \\
\hline$>4$ & $(6.020 \pm 15.497$ & $144(35)$ & $2.39)$ \\
\hline
\end{tabular}
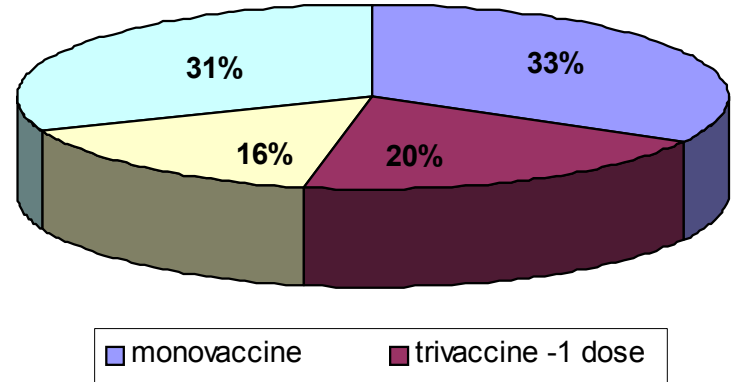

$\square$ trivaccine -2 doses $\square$ not immunized

Fig. 1. Immunization status of the tested persons
Of people showing negative results - $72(19 \%), 40$ (58\%) have been immunized once, (12\%) have been immunized with 2 doses of trivaccine; 23 (30\%) have not been immunized. It is evident that of the negative - 49 (40 +9) $(70 \%)$ were immunized (Table 2$)$.

Table 2. Distribution of the tested individuals according to their vaccination status

\begin{tabular}{|c|c|c|c|c|c|}
\hline Vaccine & $\begin{array}{c}\text { Number (n), } \\
\text { Ratio(\%) }\end{array}$ & Negative & Borderline & Positive & High positive \\
\hline $\begin{array}{c}\text { Monovaccine } \\
1 \text { dose }\end{array}$ & $\mathbf{1 3 8 ( 3 3 \% )}$ & 25 & 2 & 69 & 40 \\
\hline $\begin{array}{c}\text { Trivaccine } \\
1 \text { dose }\end{array}$ & $\mathbf{8 0 ( 2 0 \% )}$ & 15 & 6 & 36 & 20 \\
\hline $\begin{array}{c}\text { Immunization } \\
\text { and } \\
\text { reommunization }\end{array}$ & $64(16 \%)$ & 9 & 2 & 34 & 60 \\
\hline Nonimmunized & $128(31 \%)$ & 23 & 2 & 44 & 64 \\
\hline
\end{tabular}


This result questions the existence of unprotected immunized persons. This can be connected directly to the immunogenicity of the vaccine. Our data are similar to those received by some American authors [8]. This makes it possible for us to join the global discussion on discussing new ideas regarding the immunization patterns. As for the negative nonimmunized individuals - 23 (30\%), our opinion is that in all likelihood some have already had the disease in the past, and others have had the disease subclinically.

Table 2 shows also that 182 persons with positive results for $\mathrm{IgG}$, have immunological status associated with vaccine administration: $105(57 \%)$ with one dose, two doses - $34(19 \%)$ and $44(24 \%)$ - nonimmunized. The last group of nonimmunized individuals has positive results because of the natural infection. Such a conclusion can be drawn for the high positive group, comprising 144 people of whom 84 $(58 \%)$ were immunized and 60 (42\%) - , nonimmunized.

We divided the surveyed people in 4 age groups: 0
$-11,12-18,21-29$ and over 30 years of age. The distribution of the results according to the age groups is presented in Table. 3. As shown in the table, among those with negative results dominate those over 30 years of age. $-24(33 \%)$, and thoe in the group $19-29$ years of age -30 $(42 \%)$. Troublesome is the fact that 19 percent negative were found in those in child immunization age having already received two vaccines. Concerning adults over 30 , this phenomenon in all likelihood is due to gradual loss of antibodies and a rare meeting with natural infection. As to the positive group - $182(44 \%)$, it is typical that in all age groups the percentage is relatively equal - between $15 \%$ and $36 \%$. This is due both to the immunization process and the common meeting of the majority of the population with natural infection. It may be taken for granted that this group includes people with higher productivity of humural immunity. Similar conclusions can drawn for the high positive persons, too.

Table 3. Result distribution according to the age of the individuals

\begin{tabular}{|c|c|c|c|c|}
\hline $\begin{array}{c}\text { Results } \\
\text { Age groups }\end{array}$ & Negative & Borderline & Positive & High positive \\
\hline $0-11$ & $14(19 \%)$ & $6(50 \%)$ & $36(20 \%)$ & $24(17 \%)$ \\
\hline $12-18$ & $4(6 \%)$ & - & $27(15 \%)$ & $20(14 \%)$ \\
\hline $19-29$ & $30(42 \%)$ & $4(33 \%)$ & $54(29 \%)$ & $44(31 \%)$ \\
\hline Over 30 & $24(33 \%)$ & $2(17 \%)$ & $66(36 \%)$ & $56(38 \%)$ \\
\hline Altogether & $\mathbf{7 2 ( 1 0 0 \% )}$ & $12(100 \%)$ & $182(100 \%)$ & $144(100 \%)$ \\
\hline
\end{tabular}

\section{CONCLUSION:}

Based on the observed results and their interpretation, the following conclusion can be made. Seroprevalence on specific mumps IgG antibodies of the population indicates that the immune stratum in Pleven region has reached a level that should limit the epidemic spread of the disease. However, there are still diseases among the immunized persons with both mono and trivaccines. Our results were confirmed by those of the epidemiological services of the United States, Britain and other European countries in 2009. The world debate on the use of highly effective live vaccines is not over.

Our studies confirm the new concept to increase reimmunization, as demonstrated by the epidemiological practices in the last 1-2 decades. 


\section{REFERENCES:}

1. Galev, A., A. Kanev, B. Kovalev, Mumps in the Bulgarian Army (BA) in 2006 - 2007 Prophylaxis prior to and during an outbreak, Proceedings, Acute respiratory infections, IV National Conference, Pleven 2009, 103,25-33

2. Gancheva, D., and others., Clinical manifestations of mumps infection, Sofia, Medinfo, Number 03/2008, YearVIII,20-22

3. Gancheva, D., and others., Clinical manifestations of mumps infection, Proceedings Acute respiratory infections, IV National Conference, Pleven, 2009,103,5154

4. Gacheva, N. M. Kozhuharova, A. Kurchatov, Mumps in Bulgaria during the immunization period. The rise of morbidity in 1997-1998, shows the need to introduce reimmunization. Sofia, Pediatrics, Volume XXXI, 1999, 1, 13-17
5. Castilla J, Effectivness of Jeryl Lynncontaining vaccine in Spanish children, Vaccine. 2009 Mar 26, 27 (15): 2089-93 Epub 2009 Feb 12

6. James A.W., C. Polack, Understanding variation in measles-mumps-rubella immunization coverage - a population-based study, European Journal of Public Health, Vol.16, No.2, 137-142, October 5, 2005

7. Kojouharova, M., et al., Mumps outbreak in Bulgaria, in 2007: a preliminary report, Euro surveillance, Volume 12, Issue 12, 22 March 2007, http:// www.eurosurveillance.org

8. MMWR, Mumps outbreak-New York and New Jersey, June 2009-January 2010; weekly, February 12, 2010/59 (05) 125-129

9. Nardone A., et al., Sero-epidemiology of mumps in western Europe, Epidemilogy
Infect., 2003, Aug; 131 (1): 691-701

10. Sartorius, B., et al., An outbreak of mumps in Sweden, February-April 2004, Eurosurveillance, Vol.10, Issues 7-9 Jul-Sep, 2005, 191-193

11. Schmid D., et al., Mumps outbreak affecting adolescents and young adults in Austria, in 2006, Euro Survell.2006 Jun 15, 11 (6): E060615.1.

12. Spanaki A., Mumps epidemic Among Young British Citizens on the Island of Crete, Infectioun, Volume 35, Number 2 / April, 2007, Brief Report, 104-106

13. Watson-Creed, G., et al., Two successive outbreaks of mumps in Nova Scotia among vaccinated adolescents and young adults, CMAJ, August 29, 2006, 175(5), doi:10.1503/cmaj.060660

\section{Address for correspondence:}

Milena Karcheva, MD,

Department of Epidemiology, Parasitology and Tropical Medicine, Medical University - Pleven, 1, Kliment Ohridski Str., 5800 Pleven, Bulgaria

Tel: +359/64/884 269,

E-mail: milena_karcheva@abv.bg, 